\title{
VESTÍGIO DO NÃO-IDÊNTICO NA TEORIA ESTÉTICA ADORNIANA: UMA OPOSIÇÃo À DESSENSIBILIZAÇÃO DA INDÚSTRIA CULTURAL
}

\author{
[ADORNO AND THE AESTHETIC THEORY]
}

\author{
Anderson Alencar de Menezes * \\ Dalmo Cavalcante de Moura ** \\ Universidade Federal de Alagoas. Brasil
}

\begin{abstract}
Resumo: O presente trabalho tem como proposta dividir algumas inquietações acerca da estética de Adorno (1903-1969). A estética adorrniana propõe fazer uma retomada dos temas centras da análise estética e faz uma crítica as formulações mais tradicionais da estética. Kant (1989) defende a estética como parte de um juízo universal de sujeitos particulares. A obra de arte nessa estética é desinteressada. Por outro lado, Adorno (2013) observa que esse subjetivismo kantiano não responde bem as questões da estética. Sendo assim, partimos dessa crítica adorrniana para a formulação do artigo aqui. A Indústria cultural em sua estrutura utiliza-se da consciencia reificada para impossibilitar a formação plena.
\end{abstract}

Palavras-chave: Estética; juízo universal, Kant.

\section{INTRODUÇÃo}

ABSTRACT: The present work has the proposal to share some concerns about the aesthetics of Adorno (1903-1969). The adorean aesthetic proposes to make a retake of the central themes of aesthetic analysis and criticizes the more traditional formulations of aesthetics. Kant (1989) advocates aesthetics as part of a universal judgment of particular subjects. The work of art in this aesthetic is disinterested. On the other hand, Adorno (2013) observes that this Kantian subjectivism does not answer well the questions of aesthetics. Thus, we start from this adorhian criticism for the formulation of the article here. The cultural industry in its structure uses of the conscience reified to make impossible the full formation.

KEYWORDS: Aesthetics; Universal judgment, Kant.

A análise tradicional da estética determinava que a arte é produzida de A maneira desinteressada e sem uma formulação conceitual. Com o desenvolvimento da técnica e a produção a arte será ampliada com uma nova possibilidade. Essa nova possibilidade é a emancipação da arte das formas tradicionais da religião e da magia. A arte, então passou a ser autônoma.

Adorno (1903-1969) desenvolve sua obra dedicada a estética partindo de uma crítica a Kant e Hegel. Inicialmente nosso artigo busca fazer uma descrição da teoria estética de Adorno. Assim, arte é definidada como a possibilidade da

\footnotetext{
* Doutor em Ciências da Educação pela Universidade do Porto/Portugal. Licenciado em Filosofia pela Universidade Católica de Pernambuco e Mestre em Filosofia pela Universidade Federal de Pernambuco. Atualmente é Coordenador/Professor do PPGE/CEDU/UFAL e membro do GP: Filosofia e Educação/Ensino de Filosofia. ** Licenciado em Filosofia pela Universidade Federal de Alagoas. Mestre em Educação pela Universidade Federal de Alagoas. Professor da Faculdade Católica Santo Tomás de Aquino. Membro do GP: Filosofia e Educação/ Ensino de Filosofia.
} 
existente do diferente, o Não-Idêntico. O conceito de arte é mutável, porque ele é uma construção histórica. Por outro lado, as obras de arte não são apenas imitações, pois há uma relação social.

Dessa maneira, Adorno (2013) vai críticar a formulação kantiana do belo.

62 Em sua estética Kant (1989) estabelece uma estética problemática, por defender um juízo estético que seja universal a partir de sujeitos particulares. Com a ampliação da arte feita pela Indústria Cultural impõe o novo, diminuindo a capacidade dos sujeito realizarem experiência. Assim, a arte que servia para ampliar o campo dos sentido, com esse contexto passa a ser apenas mais uma mercadoria a ser explorada. O conceito de belo natural nas obras de arte traz como consequência a tentativa de reconciliação do homem e a natureza. Ao final fazemos uma relação entre arte e a Indústria Cultural.

\section{A Teoria estética de Adorno}

Na obra Teoria Estética (1970) Adorno (1903-1969) revela o caráter implícito em que a arte passou a existir. Ele aponta então, a ampliação das possibilidades da arte e faz uma análise das opiniões acerca da arte. Com o desenvolvimento das técnicas, as possibilidades do uso de vários materiais para a produção artística levou a um aumento da produção artística que também trouxe a diminuição da liberdade artística. A autonomia da arte criou a liberdade da produção livre das antigas amarras: empíricas e religiosas. Esse ideal de autonomia da arte trouxe como consequência a promessa de felicidade através da dela que não se efetivou, diante da sociedade desumanizada, dessensibilizada, segundo Adorno (2013, p. 12):

De uma tal promessa é já suspeito o próprio princípio de autonomia: ao pretender pôr uma totalidade exterior, uma esfera, fechada em si mesma, esta imagem é transferida para o mundo em que a arte se encontra e que a produz.

A arte é formada por vários momentos que se formam historicamente, ou seja, o valor de uma obra de arte não deve ser determinado pela cronologia.

Para Adorno (2013) é impossível precisar a primeira obra de arte, que segundo algumas análises da arte, tal obra seria a mais elevada, a mais pura de todas as obras. Sendo a arte uma construção histórica seu valor é mutável segundo um tempo e uma sociedade. A história revela que algo que era considerado arte, já não é mais. A análise da arte só é possível através do movimento. Esse movimento deve ir em direção aquilo que ela não é, pois o seu conteúdo é extraído de um Outro, o Não-Idêntico. Poderia essa arte, enquanto Outro, Não-Idêntico existir na sociedade de massa atual?

A arte estaria em declínio? A autonomia da arte contrapõe a sociedade do mundo do trabalho. Ela contradiz a as relações sociais do trabalho, já que a sua finalidade não é relacionado apenas às prerrogativas utilitaristas da vida. As obras vivem numa tensão entre a empiria e seu conteúdo distante já posto, pois ela é o Não-Idêntico.

As obras de arte para Adorno (2013, p. 18) são muito mais do que imitação, 
sua comunicação é realizada de maneira refratária, tendo a peculiaridade de não buscar comunicação da mesma coisa que já existe, mas fundamentar um além disso, que já está posto. A obra de arte está para além da experiência extrema coisificante.

A força produtiva estética se relaciona com o trabalho útil, já que tanto às forças produtivas quanto a estética dependem das forças sociais. Portanto, as obras de arte são tentativas de respostas àquilo que vem do exterior. Ela é motivada pelo mundo objetivo e os antagonismo não resolvidos na realidade. Ao mesmo tempo que, a obra de arte busca uma relação com o real ela também nega esse mesmo real para buscar a sua emancipação, através da revelação do Outro, conforme Adorno (2013, p. 19):

Assim, o puro conceito de arte não constituiria o circulo de um domínio garantido de uma vez por todas, mas só se produziria de cada vez, em equilíbrio e frágil, muito comparável ao equilíbrio psicológico do Ego e do Id.

Assim, as obras de arte são instantes e cada uma tem seu próprio equilibrio e a integração delas ao progresso por si mesmo, não é garantia de qualidade. A arte tem uma relação com o mundo e exerce sobre este uma força de atração. As obras de arte fazem parte da constituição do interior do homem, enquanto espaço de representação. Com o desenvolvimento no século XX a obra de arte vai perder o aspecto fantasmagórico e reforçar seu caráter de aparência. As obras de arte, então, ao mesmo tempo que se orientam pelo mundo nesse contexto deve parecer que não são fabricadas pelos homens e que se relacionam com o mundo das coisas.

Desse processo de desenvolvimento os aspectos fantasmagóricos da obra de arte vão ser afastados e em contra partida os aspectos da racionalidade instrumental vão ser ampliados, por isso as obras de arte passam a ser reificados e perdem sua pureza. Essa pureza é dada pela tensão do empírico e a representação no interior do homem. Para Adorno (2013, p. 163) as obras de arte fazem uma concessão estética ao processo de reificação, pois ao mesmo tempo em que desenvolve um conceito tenta transcende-lo, já que ela não um novo ser aí e nem apenas imitação. As obras de arte é linguagem, segundo Adorno (2013, p. 163):

Mas o meio pelo qual as obras de arte existente são mais do que a existência não é um novo ser-aí, mas a sua linguagem. As obras autênticas falam mesmo quando recusam a aparência, desde a ilusão fantasmagórica até ao último sopro aurático.

A essência da obra de arte são os seus momentos, o agrupamento desses momentos que se intercorrelacionam e assim fazem a diferença entre o elemento afirmativo da realidade e a aparência da realidade (Wirklichkeit) do sentido ao mesmo tempo em que recusa a função prática em si, porque tem que ser também secularizada para que não se torne um fetiche. A obra de arte sente o problema da aparência em sua suas obras. Tal aparência da obra de arte é o material que pela sua natureza própria se degrada e a arte busca se opor a essa degradação, porque ela através do seu conteúdo se opõe ao metafórico é expulsa o fabricado. Para Adorno (2013, p. 169) a obra de arte não tem um fim prático. Ela tem a sua expressão quando é mediatizada, Portanto a obra de arte não uma reduplicação do subjetivamente sentido. Com o mundo administrado a obra de arte passa a sofrer um novo campo de tensão. Essa tensão na modernidade cria o sujeito mutilado e 
delimita a arte, como uma arte mutilada, ou seja, sem a tensão do aspecto enigmático, pois a arte se torna uma evidência, segundo Adorno (2013, p.189) a arte não é: "de modo algum evidência".

A estética de Adorno parte de uma crítica a obra de Kant Analítica do Belo 64 (1790). O belo nessa obra é distinto da representação da imaginação. O juízo de gosto não é um juízo de conhecimento, segundo Kant (1984, p. 209):

O juízo-de-gosto não é, pois, um juízo de conhecimento, portanto não é lógico, mas estético, pelo que se entende aquele cujo fundamento-dedeterminação não pode ser outro do que subjetivo.

A definição do belo será para Kant (1984, p. 210) denominada de "minima preocupação pela existência da coisa", pois o objeto é que causa um efeito no sujeito. O fundamento da determinação do juízo-de-gosto é aquilo que, ao mesmo tempo em que é agradável e causa satisfação, não depende da formulação de um conceito, porque não é juízo de conhecimento. A sensação então, determina o contentamento a priori daquilo que o sujeito contempla, tal contentamento (Vergnögen/vergnüngen) é uma busca a priori do sujeito. Kant para Adorno (2013) formula uma estética que está baseada na satisfação. Essa satisfação desinteressada é provocada por um objeto que não possui conceito, pois não é um juízo-deconhecimento como pensa Kant (1984).

O mesmo objeto que me causa satisfação e interesse é também sem interesse e finalidade? A concepção de Kant (1989) de belo é resultado de sua filosofia como um todo, o belo é o Eu soberano capaz de alcançar a autonomia. Para Adorno (2013,p. 27) a estética kantiana é um "hedonismo castrado". O sujeito kantiano obtém prazer de algum que não se pode dá sentido, porque a estética kantiana é a estética do desinteresse. A experiência estética e a satisfação estética são apenas um detalhe, é separada do homem, no entanto é racionalizada por Kant (1989).

Portanto, há uma dificuldade imensa na estética kantiana ao colocar no subjetivismo a força integradora do mundo cheio de indivíduos particulares. $\mathrm{O}$ sujeito burguês formulado por Kant enquanto sujeito autônomo precisa do Outro para se reconhecer. A soberania do sujeito de Kant só acontece em virtude desse Outro que é colocado a margem, segundo Eagleton (1993, p.56):

Se a essência da subjetividade é a liberdade, o burguês está condenado à cegueira quando atinge mesmo o ponto mais alto de seus poderes, pois a liberdade é, por definição, incognoscível. Só o que é determinado pode ser conhecido; e de tudo o que podemos dizer da subjetividade, esta certamente não é uma de suas características.

O sujeito kantiano, embora seja o princípio explicador do mundo é expulso desse mesmo mundo. Ele conhece o mundo, mas ao mesmo tempo se coloca fora dele.

Para Eagleton (1993) Kant transforma o Outro em fenômeno, porém não estabelece quem deve conhecer quem. Portanto, a estética kantiana institui o juízo estético como resultado de uma concorrência entre os sujeitos que determinam o que a final é belo ou sublime. Esse conflito acaba quando os sujeitos alcançam a concordância. Isso implica dizer que o estético não é resultado do cognitivo, mas é resultado de um processo racional entre os sujeitos que formam a comunidade de 
sujeitos sensíveis. esta comunidade é que estabelece o que é belo e sublime.

Dessa maneira, as subjetividades formam um conjunto unívoco de valores universais recíprocos de sujeitos particulares. O paradoxo kantiano é que o mundo é tornado irracional, porque o sujeito autônomo kantiano não pode conhecer nem os outros e nem os objetos. O sujeito kantiano é, pois um sujeito cindido, ao mesmo , que é livre, faz parte de um sistema que a todo instante o aprisiona num mundo de fenômenos. O sujeito kantiano do juízo estético ao encontrar um objeto belo, busca uma unidade, harmonia, pois esse é o efeito desejado do jogo livre, segundo Eagleton (1993, p. 68):

Para Kant, a Natureza, comparativamente, não tem as qualidades de um sujeito orgânico; mas ela se conforma ao entendimento humano, e isto está a um só passo da fantasia agradável (e exigida por um conhecimento coerente) de que ela foi projetada visando esse entendimento. A estética é, assim, a esperança pálida, num ambiente crescentemente racionalizado, secularizado e desmitificado, de que não se tenha perdido inteiramente um propósito e significado último.

A estética kantiana criticada por Eagleton (1993) revela uma associação de sujeitos particulares que proclamam algo belo, sem interesse algum. Esses sujeitos formam uma subjetividade universal. O sujeito kantiano particular está predisposto a concordância mutua do prazer estético. Esse mesmo sujeito é o julgador da subjetividade universal.

Na sociedade administrada a relação do homem com a arte será modificada, se antes a relação era de contemplação passa a ser de posse. A arte então será mais uma coisa entre outras coisas. Sendo assim, o sentido passa a ser o da angústia da posse e não posse. Essa é a origem do fetiche da obra de arte como mercadoria. A arte enquanto produto do devir e faz parte como meio de prazer, assim ela é também fruição.

A arte de consumo surge dessa relação de uma arte que se torna um produto. Portanto, o momento de prazer e protesto contra o universal e o mundo imediatizado é perdido. Igualmente é perdida a relação direta entre arte e satisfação sensível, possibilitada pela arte. O sujeito criado pela sociedade administrada é o sujeito castrado, fracassado, diminuído e ressentido. A esse modelo de sujeito criase uma estética que não potencializa a mímesis, enquanto experiência primária do homem e a natureza. O sujeito é absorvido pela relação do fenômeno estético que não tem mais relação com as suas necessidades humanas, mas um subproduto de uma mímesis fracassada, segundo Adorno (2013, p. 32):

Numa sociedade onde a arte já não tem nenhum lugar e que está abalada em toda a reação contra ela, a arte cinde-se em propriedade cultural coisificada e entorpecida e em obtenção do prazer que o cliente recupera e que, na maior parte dos casos, pouco tem a ver com o objeto.

A arte menor do divertimento tão integrada, administrada e qualitativamente desfigurada, teve a sua projeção como fracasso da cultura, e apesar de criar algumas resistências, tornou-se testemunha de seu próprio fracasso. A Indústria Cultural, observando esse contexto desenvolveu muito bem a determinação de distanciamento da arte. A tendência trazida pela Indústria Cultural foi a da diminuição da distância entre o erudito e o popular. 
Dentro dessa relação a arte passa a ser uma manifestação dissonante. Essa dissonância tem origem nos atrativos ao sensível. Para Adorno (2013) o sujeito nesse contexto se torna apenas um cliente. Esse mesmo cliente não tem potencial de resistência, porque a constituição de sua consciência é reificada. Com o progresso da produção técnica a arte foi ampliada como superprodução. Com essa superprodução os bens culturais são determinados pelo prestigio, moda e caráter de mercadoria. Numa época de superprodução a arte ganhou sua autonomia, mais também passou a se desenvolver de maneira regressiva. A arte desenvolvida enquanto mais uma mercadoria não precisa mais ser o Não Idêntico, ela é agora o ser-para-outro-abstrato.

O que ofertado já é mais arte, mas um serviço fraudulento de um produto de mercadoria. Essa é a formação primária dos bens de consumo. Por isso, a mímesis é descartada dessa relação coisal, produto. A arte que antes ampliava os sentidos é organizada para submeter os sentidos de maneira reificada, impossibilitando a experiência estética.

A Indústria Cultural desenvolve a obra de arte como uma arte estandartizada, uma arte reificada, segundo Adorno (2013, p. 35):

O que é facilitado pelo facto de que, numa época de superprodução, o seu valor de uso se torna também problemático e se submete finalmente ao deleite secundário do prestígio, da moda e do próprio caráter de mercadoria: parodia da aparência estética.

Do mundo formulado sem imagem da Indústria Cultural que impõe o novo de maneira ininterrupta a arte surge como possibilitadora da restauração do encanto frente ao desencanto do mundo. A arte será mais uma área a ser explorada como lucratividade dos vários agentes administradores da arte. $\mathrm{O}$ encantamento se consolidou como desencanto, a arte nesse contexto se torna uma obra deformada pelos imperativos da consciência falsa. A arte que tinha uma relação direta com a realidade perde sua identidade dentro da sociedade falsa ela é a ilusão dos homens.

$\mathrm{O}$ mundo que passou a ser racionalizado favoreceu o vazio, pois esse mesmo mundo se tronou ao próprio homem incompreensível. O prazer estético guarda a infelicidade desse instante de mudança significativa. Por isso, o prazer será um prazer recalcado. Para Adorno $(2013$, p. 38) a arte neste instante torna-se do princípio recalcado do prazer.

Como resposta para esse conflito oriundo da Indústria Cultural em que a secularização da arte deixa de ser humana, e ao mesmo tempo passa a ser resultado de uma abundancia ilimitada, as obras de arte passam a ser o imperativo do novo. $\mathrm{O}$ novo como resposta não serve para atender a subjetividade, porque ele é somente sempre-semelhante. A arte é então, uma arte fabricada e que é classificada pelos "ismos" para ocupar um lugar de legitimidade no mercado dos bens culturais, segundo Adorno (2013, p. 41):

O Novo é o sinal estético da reprodução ampliada, justamente com a sua promessa de abundancia ilimitada.

A arte voltada para inventividade do novo, não cria nada de novo, pois a novidade é reduzida no problema de sua técnica, ou seja, de sua elaboração. Com o uso da técnica as obras de arte foram modificadas em sua relação com o tempo. A 
arte que era a possibilidade de parar o tempo, não tem mais a possibilidade de se contrapor a efemeridade. Portanto, a crise da duração é a revelação da impotência das obras de arte como mercadorias. É assim que o trágico é condenado, porque ele guarda ainda o sentido temporal da morte, declínio do finito e o sentido do sofrimento.

Portanto, a sociedade da Indústria Cultural não busca a conciliação com o tempo e a arte, o que há é uma distorção do novo, que em sua própria construção está implícito a substituição. A arte é justamente a oposição do tempo da efemeridade. A arte nesse contexto perde sua capacidade de resistência, enquanto Não-Idêntico.

A integração é apenas o subterfúgio do apequenamento da arte fabricada pelos novos mecanismos da técnica impostos pelos "ismos". Para Adorno (2013, p. 53) o sucesso da integração é igualado pela inércia e diminuição do sujeito estético que integrado passa a ser sujeito enfraquecido. A arte que era reconhecimento do ser-para-si se torna um ser-para-outros. Como podemos perceber a análise estética de Adorno é um diagnóstico altamente crítico e profundo.

O mundo que confirmava a subjetividade é afastado da possibilidade de reconhecimento de si. Tal mundo é estranho e desencantado. Por isso, a experiência deve ser diminuída, o que prevalece é o efêmero. A Indústria Cultural organiza e determina a subjugação da assimilação do sujeito, pois o autêntico e único é agora repetitivo na novidade fraudulenta do novo. $\mathrm{O}$ sujeito enfraquecido vive a decadência do excesso de realidade, segundo Adorno (2013, p. 55):

O excesso de realidade é a sua decadência: ao destruir o sujeito, mata-se a si mesma. Esta transição constitui o elemento artístico em toda a antiarte.

A relação desse mesmo sujeito com a realidade (objetividade) e a arte (subjetividade) é transformada num choque da tensão do instante que é percebido em repetição sem fim que potencializa o vazio estético. A totalidade da sociedade reflete o sistema unívoco das obras de arte como a produção do novo que repetido. Não há novidade alguma. A arte, então, é a utopia e enquanto utopia não deve ser nunca realizada, ou seja, o Novo é a sua decadência. A arte é a promessa de reconciliação entre o mundo da produção e a a promessa do paraíso na terra. Portanto, para Adorno (2013) há uma correlação entre o sistema de produção e as forças esteticamente libertadas que representam a liberdade real. No campo prático, a arte coloca uma pressão na opacidade, neutralidade da sociedade e o progresso das forças produtivas e técnicas.

Nessa organização entre sistema produtivo e a arte a experiência é perdida. Ela é absorvida pela relação de produção dominante que também domina o campo subjetivo do sujeito estético. As obras de arte correm o risco de reintroduzir a experiência para além da utilidade, segundo Adorno (2013, p. 65):

Tão flagrante se tornou a desproporção entre a cultura estabelecida e o estado das forças produtivas: socialmente, o que é um si consequente aparece como uma mudança não obrigatória para o futuro e a arte socialmente desprotegida não está de nenhum modo da sua própria validade.

A relação da arte e a sociedade analisa por Adorno (2013) é marcada pelo empobrecimento da obra de arte que é uma consequência do excesso de informação 
que promove a cultura do efêmero. Essa cultura do efêmero cria o sujeito desmotivado para a emoção estética. O sujeito racional capaz de explicar o mundo torna-se incapaz de se sensibilizar com a obra de arte. Portanto, a arte em Adorno (2013, p. 75) deve ser livre da racionalidade fins-meios e fugir do fetichismo que tais meios a coloca. Com relação a discussão sobre arte é inevitável a preocupação com o juízo de valor do que é belo do que é feio.

\section{AdORNO: O BELO E FEIO NA ARTE}

O belo e o feio aparece na Teoria Estética (2013) de Adorno. O belo e o feio na obra de arte tem relação com os aspectos sociais, já que tanto o belo como o feio são uma construção histórica. Tal conceituação ou modelo de valor foi originária da classificação das manifestações culturais dos camponeses que eram consideradas de menor valor.

Por outro lado, todo aquele que busca fazer uma crítica dessa estrutura de classificação é também nomeado feio, ou seja, toda reação a tradição foi logo estigmatizado de feio. O oprimido pelo trabalho servil, manual e corporal do campo para a tradição da análise estética era classificado como cultura atrasada. Mas a arte se recusa em ter o mundo como inamovível, a fealdade, crueldade não são apenas representações na obra de arte. Pensar a estética como a antítese do feio, ou estudo do feio é limitá-la. Ao refletir a estética como o estudo da beleza é negar o trágico, crueldade da realidade, segundo Adorno (2013, p. 85):

A imagem do belo, enquanto imagem do uno e do diverso, surge com a emancipação da angústia perante a totalidade esmagadora e a opacidade da natureza. Esse terror perante ela liberta-o o belo em si, em virtude da sua impermeabilidade frente ao existente imediato, mediante a criação de uma esfera do intocável; as obras tornam-se belas por forças da sua oposição à simples existência.

Dentro dessa tradição o grotesco, horrível e humano foram afastado da concepção de arte e que ficou num segundo plano como um Outro que não se enquadra na concepção de beleza. A arte a uma dado momento foi transformada numa anestesia do real e negação da própria realidade. Para Adorno $(2013$, p. 86) a análise tradicional da arte formalizou o belo como um instante de equilíbrio que foi sublimado, porque tal concepção de belo afasta a materialidade e seus efeitos. Portanto, o belo representa a pureza, equilíbrio.

Esse belo idealizado levou o aniquilamento do próprio belo, intocado, distante e racionalizado. Esse belo idealizado junto ao avanço da técnica na produção da obra de arte vai ocasionar uma relação entre a obra de arte e a técnica.

\section{A Obra de arte e o aVanço da técnica em Adorno}

A técnica na reflexão da Teoria Estética (2013) de Adorno. Ela surge da suspensão da interioridade imediata. Assim a técnica não é apenas uma adaptação de uma época que desenvolveu novos mecanismos de produção depois da Segunda Guerra Mundial (1933-1945). A arte passou a ser tecnificada, através do sujeito que 
teve sua consciência desiludida. A técnica faz parte de uma nova forma de organização da arte. Essa nova organização determina os fins e os meios da obra de arte. Por outro lado, a técnica não é algo espontâneo. Portanto, a relação da técnica e a obra de arte tem uma relação reciprocidade.

A tecnificação pode ser entendida como o prolongamento da natureza que aliena a linguagem imediata, segundo Adorno (2013, p. 99):

A tecnificação, braço prolongado do sujeito dominador da natureza, aliena as obras de arte da sua linguagem imediata.

Em oposição ao que é pré-fabricado do mundo midiatizado, a arte sobrepõe a natureza. A arte seria o outro daquilo que é fabricado, mas que no entanto, está posto.

O domínio da natureza que iria possibilitar benefícios e novos conhecimentos promoveu a mudança que a natureza fosse vista como algo a ser possuído. Portanto, o belo natural como experiência da natureza, foi substituído.

\section{O Belo natural}

A obra de arte enquanto produto humano se identificava com o sujeito. No entanto, a autonomia do uso de materiais resultado do progresso e em especial os objetos naturais, possibilitaram uma distância que anulou a imediaticidade, porque esse mesmo progresso enterrou tudo que não obedeceu a essa identidade.

$O$ belo natural na arte traz a tentativa de reconciliação do homem e a natureza. Para que a arte possa desenvolver uma obra de arte autentica, é preciso estabelecer uma relação com a natureza, pois a experiência genuína da arte exige uma aproximação com ela. Todo o progresso buscou a negação do componente natural.

Com o processo de urbanização do espaço, o homem se distanciou da natureza e a relação do homem com o tempo também sofrerá mudanças regidas através do apito da fábrica nas grandes cidades, segundo Adorno (2013, p. 104105):

Enquanto o progresso deformado pelo utilitarismo violentar a superfície da terra, não pode, apesar de todas as provas do contrário, impedir totalmente a percepção de que o que se situa aquém e além dessa tendência é mais humano e melhor no seu caráter retardatário.

O homem levou para a natureza um ordenamento simétrico para afastar as características próprias da natureza. A natureza desconhecida, irregular precisa ser esclarecida e dominada. Assim, da admiração à natureza como espaço de contradição com a civilização ela passou a ser o espaço de fuga, o lugar da liberdade da civilização.

Os sujeitos que buscavam a natureza, buscavam a felicidade do sujeito como um ser-para-si, que se integrava a ela em oposição a sociedade petrificada. Para Adorno (2013, p.106) a arte é articulação entre essas duas partes; o belo natural e o belo artístico. O belo natural ressalta o que ainda escapa ao domínio do homem e seus processos de racionalização do mundo. Nesse contexto o controle da natureza 
imposto pelo processo de racionalização implicou também o domínio de pessoas. Sendo assim, o belo natural vai ser tornado uma mercadoria entre tantas, e que nas obras de arte passa a ser uma caricatura de si mesmo, segundo Adorno (2013, p.109):

O belo natural, na época da sua total mediatização, transforma-se na sua caricatura; o respeito da natureza incita, perante a sua contemplação, a exercer um ascetismo enquanto o belo natural e estiver impregnado das marcas da mercadoria.

O conceito de belo natural foi modificado pela pretensão burguesa de emancipação. A experiência imediata com a natureza se libertou do sentido de troca e passou a ser neutra, fazendo com que a natureza se tornasse apenas uma reserva natural, álibi e fuga. $\mathrm{O}$ homem do progresso retraído e recalcado passa a ser o mesmo que encontra na natureza sua necessidade e sensibilidade narcisista. Esse mesmo homem vai ser a vítima fácil dos anúncios publicitários que formula a experiência miseravelmente precária. Na mudança efetuada do belo natural para o belo artístico acontece algo novo que é a promoção dessensibilização do homem em seus sentidos estéticos. Como alternativa para essa crise Adorno (2013, p.112) observa que a obra de arte traz o conhecimento adequado dos elementos estéticos e sua realização espontânea nos processos objetivos e suas tensões.

Como então classificar algo na natureza de belo e não-belo? Essa questão é feita porque o processo de conscientização do homem exigiu essa distinção, em virtude da objetividade que deve existir em tudo o que está ao redor do homem.

Diante do mundo em que o homem fábrica tudo, a natureza é aquilo que o homem não consegue fabricar. Por isso, nesse modelo de desenvolvimento o belo é aquilo que devemos perceber como compulsivamente obrigatório e incompreensível ao mesmo tempo, segundo Adorno (2013, p. 114) o belo natural é:

Ele é percebido ao mesmo tempo como algo de compulsivamente obrigatório e como incompreensível, que espera interrogativamente a sua resolução. Poucas coisas se transferiram tão perfeitamente do belo natural para as obras de arte como este duplo caráter. Sob este seu aspectos obra de arte é, em vez de imitação da natureza, uma imitação do belo natural.

Diante disso, os elementos naturais e o histórico alternam suas posições. Um pode ocupar o lugar do outro, ou seja, contrapondo as análises tradicionais Adorno (2013, p. 114) percebe que não uma unidade, mas uma tensão. Portanto, o belo natural é um devir e sua decadência é reflexo do esvaziamento da experiência histórica. O belo natural é indefinível e indeterminado. Ele é o Não-Idêntico e contrapõe a unidade universal, segundo Adorno (2013, p. 116):

A arte não imita nem a natureza, nem um belo natural singular, mas o belo natural em si. Para lá da aporia do belo natural, menciona-se aqui a aporia da estética no seu conjunto. $\mathrm{O}$ seu objetivo define-se como indeterminável, negativamente. Por isso, a arte necessita da filosofia, que a interprete, para dizer o que ela não consegue dizer, enquanto que, porém, só pela arte pode ser dito, ao não dizê-la.

$\mathrm{O}$ mundo em que a indústria produz o mesmo do mesmo, o belo natural 
representa o Não-Idêntico, diferente do produto humano fabricado. O progresso será em linhas gerais a apropriação da natureza pelo homem. Portanto, o belo natural é o vestígio do Não-Idêntico presente nas coisas ao mesmo tempo em que é uma oposição a identidade universal e faz parte de sua identidade ser disperso e incerto. O surgimento da Indústria Cultural é a perda do espaço desse Não-Idêntico. A obra de Adorno/Horkheimer Dialética do Esclarecimento (1947) traz uma análise sobre a Indústria Cultural que favorece a arte fabricada pelo uso excessivo da técnica. As mudanças ocasionadas através da ampliação da produção artística, teria levado a uma democratização ao acesso da arte. O que tal indústria fez foi acabar com a relação entre a lógica da obra e o sistema social. O agravante dessa condição é que qualquer possibilidade de discussão de criação de alternativa é logo incorporada ao sistema numa forma recalcada de cultura.

Portanto, a Indústria Cultural busca através da racionalidade a formação de um público padronizado para seus produtos também padronizados, criando inclusive uma falsa concorrência. Essa Indústria impede a formação de qualquer particularidade, pois a identidade é roubada pela organização total da subjetividade no campo simbólico da arte. Ela entorpece os sentidos ao delimitar a sensibilidade estética sob a produção do mesmo produtos para uma infinidade de clientes, segundo Adorno (1985, p 105): "Os produtos da indústria cultural podem ter a certeza de que até mesmo os distraídos vão consumi-los alertamente. Cada qual é um modelo da gigantesca maquinaria econômica que, desde o início, não dá folga a ninguém, tanto no trabalho quanto no descanso, que tanto se assemelha ao trabalho".A Indústria Cultural transformou a arte em mais um produto do entretenimento, diversão e consumo. O prazer só existe nesse contexto como promessa, segundo Adorno e Horkheimer (1985, p. 119):

se significa estar de acordo. Isso só é possível se isso se isola do processo social em seu todo, se idiotiza e abandona desde o inicio a pretensão inescapável de toda obra, mesmo da mais significante, de refletir em sua limitação o todo. Divertir-se significa sempre: não ter que pensar nisso, esquecer o sofrimento até mesmo onde ele é mostrado.

$\mathrm{O}$ que a Indústria Cultural oferece é a construção de um pseudoindividualidade, o Eu passa a ser uma mercadoria monopolizada e socialmente condicionada. Dessa maneira, a Indústria Cultural cria uma cultura inútil substituível e reproduzida como uma sociedade que não consegue perceber a relação da arte com a própria vida cotidiana. O que aconteceu foi a decadência da cultura e não a ampliação da cultura criando um sujeito com a consciência reificada. Por isso, Adorno em várias de sua obra pensa a possibilidade da Bildung (Formação Cultural) como oposição a Hallbildung (Semiformação).

\section{Considerações Finais}

A arte formulada por kant estabelece uma separação entre a arte e o social. O universalismo kantiano não serve como resposta para a estética e a explicações sobre a obra de arte. O sujeito kantiano criado segundo essa organização de uma busca pela totalidade não se comprova, porque, a unidade da obra de arte não 
existe.

A Indústria Cultural por sua vez, cria uma cultura estandartizada, padronizada que vai dirigir o campo da sensibilidade demilitando emoções e a parte cognitiva dos sujeitos.

72 A estética de Adorno coloca em discussão os paradigmas de elaboração da estética tradicional. A Indústria Cultural impõe um padrão de cultura com pretensões de ser ela universal. A produção de uma obra de arte é feita pelos seus vários momentos. A cultura reificada com potencializa a emancipação dos sujeito e pela sua organização impede qualquer alternativa de libertação dessa ordem posta. Portanto, a Indústria Cultural favorece a perda da personalidade ao desenvolver uma falsa universalidade do gosto estético, colocando fim na construção de um sujeito estético.

Assim, a Indústria Cultural não visa a acumulação da experiência, mas a imediaticidade. A Teoria Estética publicada em (1970) de Adorno é uma constatação do aprofundamento da decadência da cultura.

\section{REFERÊNCIAS}

ADORNO, Theodor W. Dialética do Esclarecimento: Fragmentos filosóficos. Rio de Janeiro. Paz e Terra, 1995.

ADORNO, Theodor W. Teoria Estética. Edições 70. Lisboa, Portugal. 2013.

EAGLETON, Terry. A ideologia da Estética. Rio de janeiro: Zahar, 1993.

KANT, Immanuel. Analítica do belo e da arte e do gênio. In: Texto selecionados. 2. ed. São Paulo: Abril Cultural, 1984. 